\title{
EXTENT OF SOLAR TRACKING DIFFERS BETWEEN TWO CO-OCCURRING CONGENERIC GEOPHYTES THAT DIFFER IN LEAF SHAPE
}

\author{
Kerri Mocko,* Adrienne B. Nicotra, + and Cynthia S. Jones ${ }^{1, *,} \dagger$ \\ *Department of Ecology and Evolutionary Biology, University of Connecticut, Storrs, Connecticut 06269-3043, USA; and +School of Botany \\ and Zoology, Australian National University, Canberra, Australian Capital Territory 0200, Australia
}

Editor: Hafiz Maherali

\begin{abstract}
Premise of research. By adjusting leaf angles to orient toward or away from the sun, solar tracking modifies direct light interception, which consequently modifies leaf temperature. Leaf temperature is also influenced by leaf shape, due to its effect on heat transfer across boundary layers. Two co-occurring, closely related geophytic species of Pelargonium that differ dramatically in leaf shape were observed to exhibit differences in diurnal leaf movements. We asked whether leaf movements were consistent with solar tracking, whether they differed between the two species, and whether leaf shape and movement interacted to influence leaf temperature.
\end{abstract}

Methodology. We measured solar tracking, leaf temperatures, stomatal conductance, and light interception across a diurnal time course in midwinter in the field at De Hoop Nature Reserve in South Africa.

Pivotal results. Highly dissected leaves of $P$. triste moved to track the sun more closely than shallowly lobed leaves of P. lobatum. In contrast to predictions based on leaf energy budget calculations, average diurnal temperatures for both leaf shapes remained close to ambient, with the only significant deviation occurring early in the morning in P. triste. The best model predicting the extent of leaf temperature difference from ambient included leaf shape, leaf movement, and the proportion of the leaf surface receiving direct light, and, notably, the interaction between leaf shape and movement.

Conclusions. Leaf three-dimensionality interacts with movement to dictate direct light absorption, and all are critical to fully understanding leaf thermal profiles of nonflat leaves under field conditions.

Keywords: leaf temperature, light interception, Pelargonium, solar tracking, South Africa, three-dimensional leaf shape, leaf shape, leaflet.

Online enhancements: appendix figures and tables.

\section{Introduction}

More than a century ago, Darwin (1881, p. 443) recognized that solar tracking provides a "service to the plant." Generally defined as controlled, reversible movement orienting plant organs either toward or away from the sun, the service depends on environmental context. Under cool temperatures and low water stress, diaheliotropic movements maintain leaves perpendicular to incident light, thereby maximizing direct solar radiation incident on the leaf and increasing leaf temperatures. Under warmer, dryer conditions, paraheliotropic movements position leaves parallel to solar incidence to reduce photon flux density, prevent thermal and photo damage, and enhance water use efficiency (Ehleringer and Forseth 1980, 1989; Ehleringer and Werk 1986). The type of movement can shift across seasons

1 Author for correspondence; e-mail: cynthia.s.jones@uconn.edu.

Manuscript received July 2017; revised manuscript received October 2017; electronically published December 29, 2017. and diurnally. Over the course of a day, for example, diaheliotropic movement can position leaves to intercept more light in the morning but later switch to paraheliotropic movement that then positions leaves to avoid direct sunlight in the middle of the day (e.g., Forseth and Ehleringer 1982; Forseth and Teramura 1986; Pritchard and Forseth 1988; Joesting et al. 2012; Foster et al. 2013). Studies have demonstrated that diurnal leaf movement can benefit leaf carbon gain (Mooney and Ehleringer 1978; Forseth and Ehleringer 1983; Greer and Thorpe 2009; Zhang et al. 2009; Habermann et al. 2011) and increase seed production (dos Santos et al. 2006).

Leaf angles determine the angle of direct solar radiation incident on leaves (Gates 1980) as well as the relative proportions of the leaf surface in direct light versus shade for a given leaf shape and thus leaf temperature (Medina et al. 1978; Werk and Ehleringer 1984; Forseth and Teramura 1986; ValienteBanuet et al. 2010). A further determinant of light absorption is that leaves are seldom flat and leaf angle varies across the leaf (Fleck et al. 2003), which also influences leaf temperature (Forseth and Ehleringer 1980; Kern et al. 2004) via internal leaf 
self-shading. Much more attention has been paid to inter- than intraleaf self-shading, so at this point we still lack a complete picture of the functional consequences of leaf three-dimensionality (but see Chelle 2005; Pincebourde et al. 2012).

The functional significance of two-dimensional leaf shape is generally attributed to thermal regulation (but see Nicotra et al. 2011; Leigh et al. 2014). Studies demonstrating links between shape and temperature are generally conducted on artificial leaves in uniformly illuminated, highly controlled conditions (Vogel 1970; Parkhurst and Loucks 1972; Gottschlich and Smith 1982; Schuepp 1993). Under such conditions, the thickness of the boundary layer (the insulating layer of dead air space over the surface of the leaf) is related to wind speed and leaf width in the direction of airflow (Nobel 1983; Schuepp 1993). Incorporating boundary-layer resistance into leaf energy budget equations predicts that larger leaves will reach higher temperatures than smaller leaves or leaflets with thinner and more broken boundary layers (Parkhurst and Loucks 1972), but both the magnitude and the direction of this effect depend on the difference between leaf temperature and ambient air temperature (Gates 1980).

Leaf temperatures in the field can be several degrees cooler or warmer than ambient (Gates 1980; Geller and Smith 1982; Leigh et al. 2017), especially if based on single point measurements. There also can be large temperature differences between local regions within the leaf (Smith and Nobel 1978; Vogel 2009; Leigh et al. 2017), presumably due to self-shading, the extent of patchy stomatal conductance, and the water content of the leaf (Leigh et al. 2017). These confounding factors may explain why some studies have shown that average leaf temperatures of a wide array of shapes often differ less than $3^{\circ} \mathrm{C}$ from ambient and that leaf temperatures can track ambient very closely under field conditions that support latent heat loss through transpiration, even when wind speeds are low (Gates et al. 1968; Hegazy and El Amry 1998; Valiente-Banuet et al. 2010; Leigh et al. 2017). However, when latent heat transfer is minimal, even average leaf temperatures of wide leaves can be several degrees above ambient (Leigh et al. 2017).

During the wet, cool winter growing season in the Cape Floristic Region of South Africa, we observed differences in the extent to which leaves moved during the day in two species of Pelargonium differing in leaf shape but growing next to each other at De Hoop Nature Reserve. Pelargonium lobatum has large, shallowly lobed leaves ( 4-cm effective leaf width $\left.\left[w_{\mathrm{e}}\right]\right)$ with palmate venation, while $P$. triste has pinnately dissected compound blades composed of small ( 0.1-cm-wide) leaflets (fig. 1). If observed movements are consistent with solar tracking, then in the winter growing season diaheliotropic solar tracking should warm leaves of both species above ambient; boundary-layer theory predicts $P$. triste should remain closer to ambient. We hypothesized that if species differ quantitatively in solar tracking, we should see evidence of an interaction between solar tracking and leaf shape on diurnal leaf temperatures that would closely match leaf energy balance predictions. To compare the effect of leaf shape, angle, and movement on realized thermal dynamics of leaves, we ask the following questions: (1) Do the species' leaves move to different extents, and are the directions and amount of movements consistent with solar tracking? (2) Do average leaf temperatures under field conditions follow temperatures predicted by leaf energy budget equations? (3) Does solar tracking raise leaf temperatures by increasing the proportion of direct light absorption, as expected? (4) Which combination of variables (leaf angle and azimuth; functional leaf traits such as leaf size, shape, or specific leaf area (SLA); or the proportion of the leaf in direct sunlight) best predicts average leaf temperature?

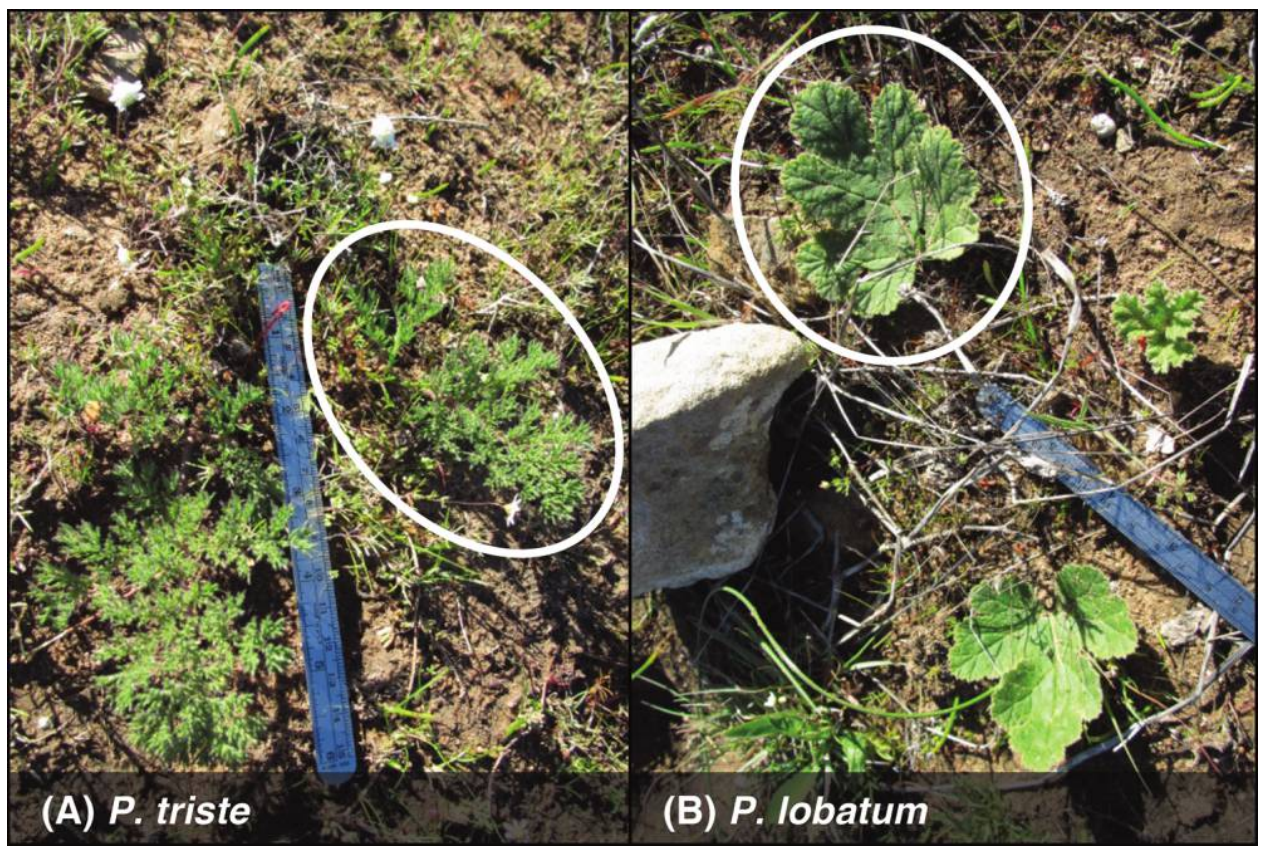

Fig. 1 Pelargonium triste $(A)$ and Pelargonium lobatum $(B)$ growing in the same site at De Hoop Nature Reserve in South Africa. Each plant has three leaves; one recently fully expanded leaf is indicated by the white circles. 


\section{Material and Methods}

Our site at the De Hoop Nature Reserve (lat. 34²6'39.1"S, long. $20^{\circ} 25^{\prime} 16.9^{\prime \prime} \mathrm{E}$ ) is characterized by fynbos vegetation (Cowling et al. 1997) dominated by proteas and restios growing on light brown sandy soils (fig. 1). Average rainfall in July at this site is $46 \mathrm{~mm}$, and mean annual temperatures are $\sim 17^{\circ} \mathrm{C}$ (Schulze 2007). Pelargonium triste and P. lobatum are closely related (Bakker et al. 2004) and often grow within $1 \mathrm{~m}$ of each other in patchily open microsites. Pelargonium lobatum flowers in late spring (September-November), while P. triste flowers from midwinter through midsummer (August-February; Goldblatt and Manning 2000). Both are winter-growing, summer deciduous geophytic perennials, the leaves of which arise from belowground tubers; consequently, leaf orientations are not influenced by branch architecture. Pelargonium species do not have pulvini (C. S. Jones, personal observation) and thus fall into the group of solar tracking species that achieve leaf movements through petiole twisting (Galvez and Pearcy 2003) or changes in turgidity in cells across the leaf (van Zanten et al. 2010).

\section{Field Measurements}

We followed movement of one leaf per plant on five individuals per species every $2 \mathrm{~h}$ from 0900 to 1700 hours on July 22, 2008. Leaf angle was measured as the angle of inclination from horizontal of the lamina midrib, using a protractor and straightedge. For leaf azimuth, we used a compass to find the direction toward which the majority of the adaxial leaf surface faced at the time of measurement.

We measured adaxial leaf temperatures using a recently calibrated Optris LaserSight (Optris, Berlin) infrared thermometer with a spot size of $1 \mathrm{~mm}$, holding the thermometer $\sim 10-20 \mathrm{~cm}$ from each leaf, perpendicular to the surface at the measurement location. Emissivity on the laser thermometer was factory set to 0.95 , within the range of known values for leaves (e.g., López et al. 2012). We took four measurements $1 \mathrm{~cm}$ to the left of the midrib, evenly spaced along its length, and one measurement closer to the margin of the lamina near midlength. Average temperatures per leaf were calculated from these point measures for each time period. For each measurement, we also noted whether the measurement point was taken on the portion of the leaf in direct light, diffuse light, or shade, based on observation. Ambient air temperature was recorded prior to each set of measurements on each leaf from a thermometer in the shade, $1 \mathrm{~m}$ above the soil surface. Wind speeds were estimated at $1 \mathrm{~m} \mathrm{~s}^{-1}$. Leaves were photographed (face-on view) at each measurement to determine the extent of shading over the lamina.

Soil surface temperature adjacent to each leaf but unshaded by the plant or other vegetation was estimated with the laser thermometer and closely tracked ambient. We acknowledge that because we did not take soil emissivity or reflectance into account, our measurements may not represent actual soil surface temperature. However, damp, sandy soils can be close to, or even slightly below, ambient air temperatures (Nobel and Geller 1987). Percent soil moisture was determined gravimetrically from an average of five samples collected $7-10 \mathrm{~cm}$ below the soil surface. We measured stomatal conductance of both leaf surfaces at midday with a steady-state diffusion porometer (Decagon Leaf Porometer model SC-1, Pullman, WA) on each individual leaf.

\section{Leaf Morphology}

All measured leaves were collected at the end of the day. Flattened lamina area $\left(\mathrm{cm}^{2}\right)$ of fresh leaves was measured with a Li-Cor 3100 leaf area meter (Li-Cor, Lincoln, NE). Lamina dimensions (outline dimensions of length and width, excluding dissection) were measured with a ruler. On fresh leaves, we also measured effective leaf width $\left(w_{\mathrm{e}}\right)$, the diameter of the largest inscribable circle within the lamina (McDonald et al. 2003). We dried laminae to obtain dry masses and calculated SLA $\left(\mathrm{cm}^{2} \mathrm{~g}^{-1}\right)$ as the ratio of fresh leaf area to dry leaf mass. We obtained lamina perimeters from face-view leaf images using the Measurement tool in Adobe Photoshop CS4 Extended (2008). We quantified leaf shape using a continuous leaf dissection index (LDI), the ratio of lamina perimeter to the square root of flattened lamina area. We used Photoshop also to determine projected lamina area (unflattened leaves retain their original three-dimensional shape) from photographs of leaves in the field taken perpendicular to the plane of the leaf midrib. We quantified leaf threedimensionality as the difference between total flattened lamina area and projected area.

\section{Leaf Light Interception Calculations}

Solar tracking takes into account not only leaf angle but also leaf azimuth and, most importantly, the angle of the sun. This combined index, the cosine of interception (cosine $i$ ), explicitly quantifies the proportion of the sun's direct beam that a leaf can potentially capture (Forseth and Teramura 1986). Cosine $i$ is determined as follows:

$$
\cos i=\cos \beta \times \sin E+\sin \beta \times \cos E \times \cos \left(\alpha_{\mathrm{s}} \times \alpha_{\mathrm{l}}\right),
$$

where $\beta=$ leaf angle from horizontal, $E=$ solar elevation, $\alpha_{\mathrm{s}}=$ solar azimuth angle, $\alpha_{1}=$ leaf azimuth angle. A cosine $i$ absolute value of 1 represents the condition when the leaf blade is oriented perpendicularly to the sun's direct beam for maximum direct light interception. Cosine $i$ values approach zero when the leaf blade is parallel to the sun's radiation and there is little potential for direct light capture (Pritchard and Forseth 1988; Rosa and Forseth 1996). Solar elevation and azimuth data were obtained from the National Oceanic and Atmospheric Administration Earth System Research Lab solar position calculator (Cornwall et al. 2014).

\section{Leaf Energy Balance Calculations}

Prior to calculating leaf energy balance, we estimated the leaf shape parameter $\left(K_{1}\right)$, using the single leaf model described by Balding and Cunningham (1976) assuming that aggregates of leaflets were not functioning as a whole leaf (see fig. A1 for calculations; figs. A1-A5 are available online). We then used an energy budget equation (Sousa 2003) to predict temperatures of individual leaves for both species throughout the day; these predictions incorporated observed movements and stomatal conductance. (See table 1 for the equation and a breakdown of mea- 
Table 1

Leaf Energy Balance Equation Used to Calculate Leaf Temperatures for Tracking and Stationary Leaves

\begin{tabular}{ll}
\hline Variables & \multicolumn{1}{c}{ Definitions } \\
\hline Outcome variable: & Leaf temperature (calculated hourly per leaf for tracking and stationary leaves) \\
$T_{1}$ & Air temperature (measured hourly per leaf) \\
Variables measured directly: & Absorption coefficient to solar radiation \\
$T_{\mathrm{a}}$ & Leaf length in the direction of the wind (measured per leaf) \\
$\varepsilon$ & \\
$w$ & Direct + diffuse + long-wave radiation (calculated hourly per leaf) \\
Calculated variables: & Water vapor density of air (calculated hourly per leaf) \\
Total energy in & Leaf resistance to water vapor (calculated hourly per leaf) \\
$e_{\mathrm{a}}$ & Leaf shape parameter (calculated per leaf) \\
$r_{1}$ & Convection coefficient: thermal conductivity coefficient for air $\div$ boundary layer thickness \\
$K_{1}$ & (calculated hourly per leaf) \\
$h_{c}$ & Slope of vapor pressure-temperature curve (calculated hourly per leaf) \\
$\Delta$ & Stephan Boltzman constant (blackbody radiation constant) \\
Constants: & Latent heat of vaporization \\
$\sigma$ & Diffusion coefficient for water vapor \\
$L$ & Wind velocity (estimated at 1 m s ${ }^{-1}$ ) \\
$D_{j}$ &
\end{tabular}

Note. Variables are separated into those measured directly in the field, those calculated, and those held constant. Energy balance equation (Sousa 2003): $T_{1}=T_{\mathrm{a}}+\left(\left(\right.\right.$ Total Energy In/2 $-\left(\varepsilon^{*} \sigma *\left(\left(T_{\mathrm{a}}+273.15\right)^{4}\right)\right)-\left(\left(L^{*}\left(23-e_{\mathrm{a}}\right)\right) /\left(r_{1}+\left(K_{\mathrm{l}} *\right.\right.\right.$ $\left.\left.\left.\left.\left.\left((w / v)^{0.5}\right) / D_{\mathrm{j}}\right)\right)\right)\right) /\left(4^{*} \varepsilon^{*} \sigma^{*}\left(\left(T_{\mathrm{a}}+273.15\right)^{3}\right)+h_{\mathrm{c}}+\left((L * \Delta) /\left(r_{1}+\left(K_{\mathrm{l}} *\left((w / v)^{0.5}\right) / D_{\mathrm{j}}\right)\right)\right)\right)\right)$.

sured and calculated variables.) We also calculated expected leaf temperatures for leaves that did not move during the day (i.e., by setting leaf inclination to zero to simulate leaves positioned flat on the ground).

\section{Image Analysis of Leaf Surface Light Regime}

We used Photoshop to categorize light incident on the surface of the leaf at each measurement period across the diurnal time course (fig. A2) as direct, diffuse, or shade using the Threshold command and color matching for individual pixels across the lamina. We used the Magic Wand selection tool to select and calculate the total areas of light category. In the analysis, we did not distinguish between self-shading and shading caused by adjacent vegetation because all plants were relatively exposed, so nearly all shade was due to within-leaf self-shading. Because images were obtained on a sunny day, we assume the diffuse light is due to penumbra.

\section{Statistical Analyses}

Leaf temperature data and solar tracking responses were analyzed using two different approaches. We used ANOVA (R Development Core Team 2012) to compare interspecific differences in individual leaf traits and light regime at each time point during the day. We used the generalized additive mixed models (GAMM) function from the mgcv package (Wood 2017) to fit models for $\Delta T$, the difference between leaf temperature and air temperature. To determine which variables best predicted $\Delta T$, we took into account repeated measurements on each leaf and included hours (time since 0900 hours), cosine $i$, SLA, lamina area, lamina dry mass, LDI, and proportional lamina area in direct light, diffuse light, and shade. We compared models using the Akaike information criterion (AICc), which is a test statistic that compares the goodness of fit for models and adjusts for small sample sizes.

\section{Follow Up}

To determine whether conductance values changed over the course of the day, we returned to the same site at De Hoop Nature Reserve (same $20 \mathrm{~m}^{2}$ area) in July 2015. We measured five individuals per species (we do not know whether these were the same individuals measured in 2008). Diurnal stomatal conductance was measured every $2 \mathrm{~h}$ between 1000 and 1600 hours. In 2015, we used a Li-Cor 6400XT with a $\mathrm{CO}_{2}$ mixing system and a red/blue LED light source. Light level was maintained at saturating levels, $1500 \mu \mathrm{mol} \mathrm{m}^{-2} \mathrm{~s}^{-1}$. Flow was set at $500 \mu \mathrm{mol} \mathrm{s}^{-1}$ and $\mathrm{CO}_{2}$ at $400 \mu \mathrm{mol} \mathrm{mol}^{-1}$. Chamber humidity was maintained slightly below ambient. We made three gas exchange measurements per leaf: the first measurement was made when gas exchange values began to settle (typically after about $2 \mathrm{~min}$ ), and subsequent measurements were taken each minute afterward or when values stabilized (the leaf was generally in the chamber for about 5 min total). We averaged these three readings to determine the mean conductance rate per leaf. These conductance values were analyzed with repeated-measures ANOVA to test for differences between species and hours.

At every plant during every measurement, ambient air temperature and wind speed were measured at the leaf level with a portable handheld weather station (Kestrel 3500; Kestrel Meters, Birmingham, MI), 5-10 cm above the soil surface. We also collected leaves and obtained both fresh and dry weights, as well as leaf areas, to calculate water content per unit area (succulence). 


\section{Results \\ Leaf Morphology}

Leaves of Pelargonium triste and P. lobatum were similar in length and width of their overall lamina outlines, but leaves of $P$. lobatum had larger areas and were wider, heavier, and much less dissected than leaves of $P$. triste; SLA values were higher for $P$. lobatum, but water content per unit area was higher in leaves of $P$. triste (table 2). Both P. triste and P. lobatum leaves exhibited three-dimensional structure that we quantified as the difference between total flattened and projected lamina area (D). This difference was $\sim 4.5 \mathrm{~cm}^{2}$ for both species, although this was a larger proportion of the total lamina area for $P$. triste $(29 \%)$ than P. lobatum (9.9\%).

\section{Stomatal Conductance}

Weather conditions were similar in both 2008 and 2015: both days were mostly sunny with a similar daytime range in ambient temperature $\left(13.6^{\circ}-20.2^{\circ} \mathrm{C}\right.$ in 2008 and $12.8^{\circ}-$ $22.2^{\circ} \mathrm{C}$ in 2015). In 2015 , wind speed values at leaf level ranged from 0 to $2 \mathrm{~m} \mathrm{~s}^{-1}$ with an average value over the course of the day of $0.6 \mathrm{~m} \mathrm{~s}^{-1}$, indicating that our estimate of $1 \mathrm{~m} \mathrm{~s}^{-1}$ for the leaf energy budget calculations was reasonable. Average gravimetric soil moisture content was $16.5 \% \pm$ $0.02 \% \mathrm{SD}$, which is in the range of field capacity for sandy soils.

Li-Cor measurements of conductance in 2015 were higher, on average, than the 2008 porometer measurements $\left(F_{1,40}=\right.$ $3.82, P=0.06$ ) but did not differ significantly between species on either date (2008: $F_{1,6}=1.89, P=0.22$; 2015: $\left.F_{1,25}=0.42, P=0.52\right)$. Diurnal measurement values $(1000$ 1600 hours) ranged from 0.361 to $0.594 \mathrm{~mol} \mathrm{H}_{2} \mathrm{O} \mathrm{m}^{-2} \mathrm{~s}^{-1}$ for $P$. triste and from 0.344 to $0.545 \mathrm{~mol} \mathrm{H}_{2} \mathrm{O} \mathrm{m} \mathrm{m}^{-2} \mathrm{~s}^{-1}$ for $P$. lobatum. Time of day had a significant effect on conductance $\left(F_{3,25}=3.74, P=0.02\right)$, but this effect was the same in both species (fig. A3).

\section{Species' Leaves Moved Differently but Were Consistent with Solar Tracking}

Leaves of both species were horizontal to the ground at 0700 hours and then inclined significantly during the day $\left(F_{4,32}=5.05, P=0.003\right)$. The largest increase in inclination for both species occurred between 0700 and 0900 hours; that in $P$. triste was substantially greater. Overall, $P$. triste inclined more than $P$. lobatum (maximum inclination $47^{\circ}$ compared to $24^{\circ}$, respectively; $F_{1,8}=9.09, P=0.02$; fig. $2 A$ ). Both species exhibited steepest leaf inclination at midday (1300 hours). There were also changes in leaf azimuth of both species throughout the day $\left(F_{4,32}=4.43, P=0.006\right)$, but there were no differences between species in mean azimuthal change $\left(F_{1,8}=\right.$ $1.53, P=0.25)$; i.e., leaves of both species exhibited similar extents of rotation.

These leaf movements ultimately resulted in differences in the degree of diurnal solar tracking between $P$. triste and $P$. lobatum, quantified by cosine $i$ (fig. 2B): $P$. triste oriented to intercept more of the sun's direct beam than $P$. lobatum $\left(F_{1,8}=7.33, P=0.03\right)$. Maximum orientation to incident light in P. triste occurred at 1100 hours and resulted in a potential interception of $86 \%$ of the sun's direct beam (average maximum cosine $i: 0.86$ ). Maximum orientation in $P$. lobatum occurred at 1300 hours and resulted in a potential interception of $54 \%$ incident light. Cosine $i$ changed for both species throughout the day $\left(F_{4,32}=8.73, P<0.001\right)$.

\section{Average Leaf Temperatures Were Lower than Leaf Energy Budget Predictions}

Leaf energy budget calculations based on ambient temperatures, observed leaf orientations, lamina widths, and stomatal conductance measured at midday in 2008 predicted that $P$. triste would warm to $22^{\circ} \mathrm{C}$ at midday when ambient temperature reached $20^{\circ} \mathrm{C}$ (fig. $3 \mathrm{~A}$ ) and that $P$. lobatum leaves would reach nearly $28^{\circ} \mathrm{C}$ (fig. $3 B$ ). To explore whether the higher Li-Cor values for conductances and their diurnal vari-

Table 2

Mean Leaf Traits for Pelargonium triste and Pelargonium Iobatum

\begin{tabular}{|c|c|c|c|c|c|}
\hline Leaf traits & P. triste & P. lobatum & df & $F$ & $P$ \\
\hline Lamina length $(\mathrm{cm})$ & $10.3 \pm 1.5$ & $9.4 \pm .9$ & 1,8 & .23 & .64 \\
\hline Lamina width $(\mathrm{cm})$ & $8.8 \pm .8$ & $10.4 \pm .9$ & 1,8 & 1.78 & .22 \\
\hline Lamina area $\left(\mathrm{cm}^{2}\right)$ & $20.5 \pm 3.4$ & $48.1 \pm 8.4$ & 1,8 & 9.28 & .016 \\
\hline Lamina dry mass (g) & $.23 \pm .03$ & $.42 \pm .06$ & 1,8 & 8.56 & .019 \\
\hline Water content/area $\left(\mathrm{g} \mathrm{cm}^{-2}\right)$ & $.057 \pm .003$ & $.042 \pm .002$ & 1,22 & 20.24 & $<.001$ \\
\hline Specific leaf area $\left(\mathrm{cm}^{2} \mathrm{~g}^{-1}\right)$ & $87.4 \pm 7.0$ & $113.1 \pm 6.0$ & 1,8 & 7.67 & .024 \\
\hline Leaf dissection index & $31.4 \pm 1.7$ & $7.2 \pm .3$ & 1,18 & 200 & $<.001$ \\
\hline Effective leaf width $\left(w_{\mathrm{e}} ; \mathrm{cm}\right)$ & $.10 \pm .00$ & $3.90 \pm .29$ & 1,8 & 169.9 & $<.001$ \\
\hline $\mathrm{D}\left(\right.$ flat - projected lamina area; $\left.\mathrm{cm}^{2}\right)$ & $4.5 \pm .5$ & $4.3 \pm .4$ & 1,34 & .10 & .76 \\
\hline $\mathrm{D}_{\%}($ flat - projected lamina area; $\%$ of total area $)$ & $29.0 \pm 4.4$ & $9.9 \pm 1.2$ & 1,34 & 23.5 & $<.001$ \\
\hline Abaxial stomatal conductance $\left(\mathrm{mmol} \mathrm{H}_{2} \mathrm{O} \mathrm{m}^{-2} \mathrm{~s}^{-1}\right)$ & $205 \pm 68$ & $98 \pm 16$ & 1,6 & 2.33 & .18 \\
\hline Adaxial stomatal conductance $\left(\mathrm{mmol} \mathrm{H}_{2} \mathrm{O} \mathrm{m}^{-2} \mathrm{~s}^{-1}\right)$ & $184 \pm 25$ & $147 \pm 41$ & 1,6 & .62 & .46 \\
\hline Total stomatal conductance $\left(\mathrm{mmol} \mathrm{H}_{2} \mathrm{O}^{2} \mathrm{~m}^{-2} \mathrm{~s}^{-1}\right)$ & $389 \pm 89$ & $245 \pm 56$ & 1,6 & 1.89 & .22 \\
\hline
\end{tabular}

Note. Values represent the mean of five leaves \pm 1 SE. $F$ and $P$ values of ANOVA comparing species. Note that degrees of freedom for morphological traits are based on leaves sampled. Degrees of freedom for changes in leaf three-dimensionality are based on all photos over the diurnal time course. All data are based on 2008 data except water content/area (succulence), which was measured in 2015. 

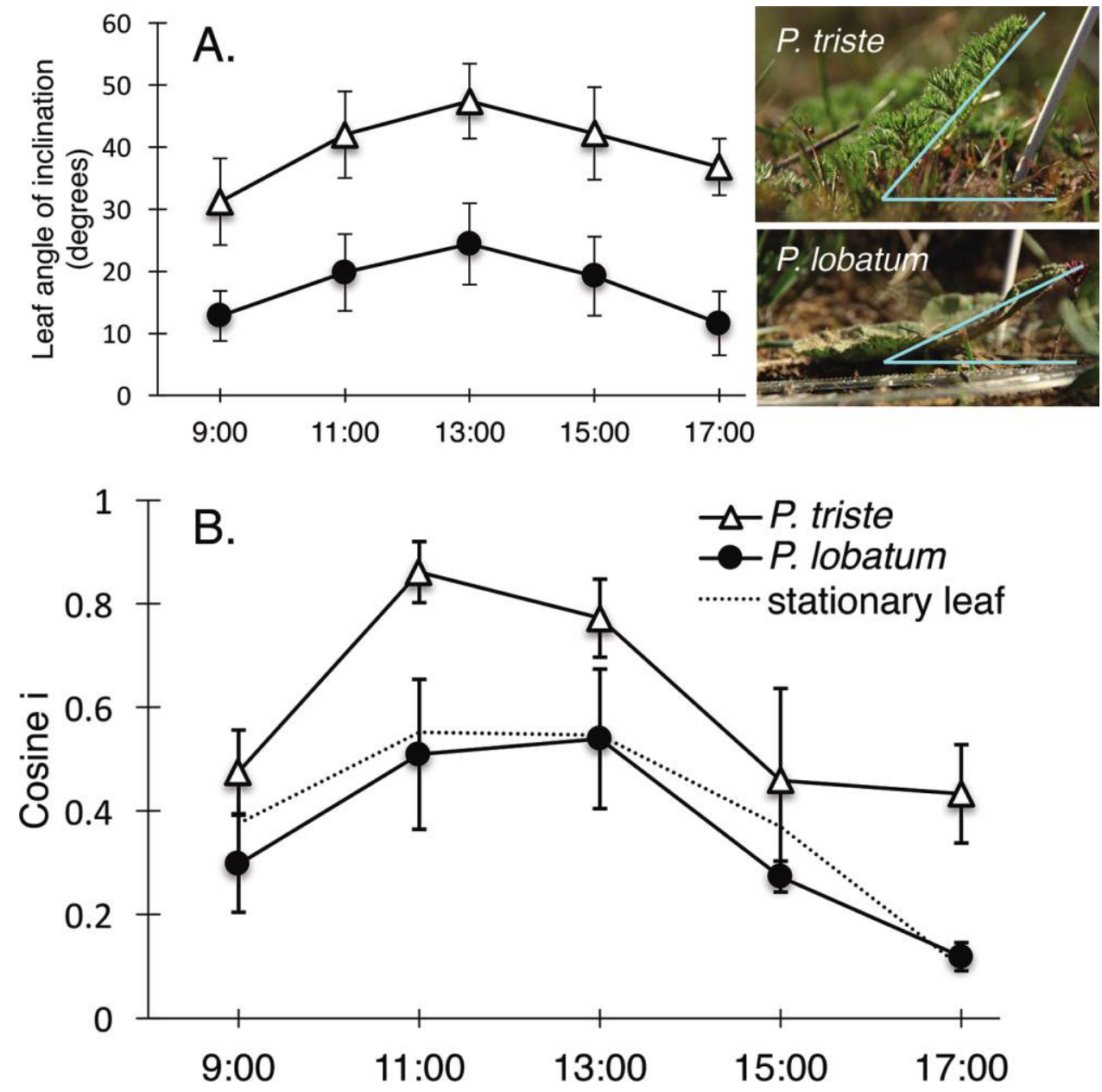

Fig. 2 A, Diurnal change in leaf inclination for Pelargonium triste (open triangles) and Pelargonium lobatum (filled circles). Symbols represent mean of five leaves and error bars $\pm 1 \mathrm{SE}$. Side-view photographs at 1300 hours show maximum angles of leaf inclination for both species. $B$, Cosine $i$ shows the degree of solar tracking for $P$. triste and P. lobatum; symbols and error bars same as $A$. Cosine $i$ values approach zero when the leaf blade is parallel to the sun's radiation and there is little potential for direct light capture. Cosine $i=1$ represents maximum solar attraction (leaf orientation is perpendicular to the sun). Cosine $i$ changes diurnally for a stationary, horizontal leaf (dotted line) because the angle of incidence between the sun and the leaf changes as the sun moves across the sky during the day.

ation measured in 2015 would have changed these results, we substituted them into the 2008 leaf energy budget calculations, keeping all other parameters the same. This substitution did not change the predicted values (fig. A4). When we modeled no leaf movement by setting leaf inclination to zero, temperatures of $P$. lobatum leaves were predicted to be the same as in leaves that moved, while stationary $P$. triste leaves were predicted to be more than a degree cooler throughout the day than tracking leaves. In other words, movement in the highly dissected leaves of $P$. triste led to predictions of leaf temperatures that would be warmer than stationary leaves.

In contrast to predicted temperatures, observed leaf temperatures were similar in each species at most measurement times and they remained close to air temperatures (fig. 3C; table 3). Soil temperatures were also close to ambient and leaf temperatures $\left(F_{1,81}=0.39, P=0.54\right.$; see fig. $3 C$, inset $)$. Leaf temperatures between species were most different in the early morning, at 0900 hours when $P$. triste leaves were, on aver- age, $3.6^{\circ} \mathrm{C}$ warmer than $P$. lobatum leaves. At the end of the day, $P$. lobatum leaves were significantly cooler than ambient at 1700 hours (table 3).

\section{The Interaction of Shape and Movement Affected Direct Light Exposure}

Solar angles have varying effects on the proportions of direct light, diffuse light, and shade on leaf surfaces. As expected, time of day affected the amount of direct light interception $\left(F_{4,22}=21.81, P<0.001\right)$ and the amount of shade on leaves of both species $\left(F_{4,22}=5.07, P=0.005\right)$, while the proportion of leaf surface area with diffuse light remained constant throughout the day $\left(F_{4,22}=1.39, P=0.27\right)$. Both species had similar total daily proportions of leaf surfaces experiencing direct light $\left(F_{1,3}=0.00, P=0.99\right)$, but the pattern of direct light interception differed between species over the course of the day (fig. $4 ; F_{4,22}=2.90, P=0.05$ ). In contrast, species 


\section{(A) P. triste predictions}

\section{(B) P. lobatum predictions}

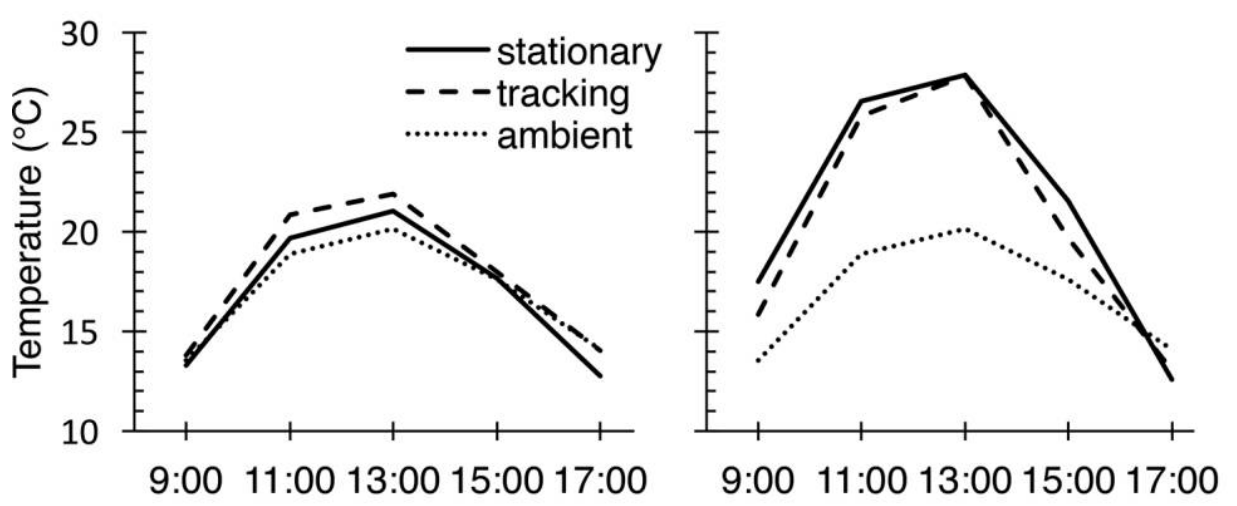

(C) Field measurements

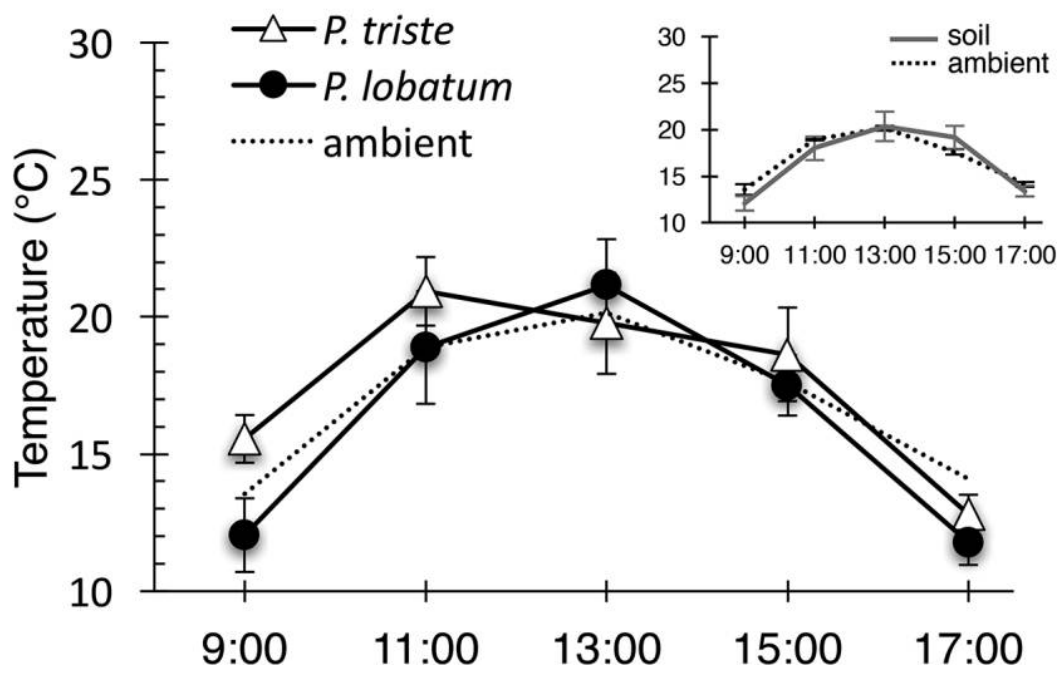

Fig. 3 Predicted leaf temperatures for Pelargonium triste $(A)$ and Pelargonium lobatum $(B)$ based on energy budgets for stationary leaves (solid line) and tracking leaves (dashed line). The dotted line shows measured ambient temperature throughout the day. $C$, Actual measured leaf temperatures of $P$. triste and $P$. lobatum during the day; symbols represent mean of five leaves and error bars \pm 1 SE. Inset shows that soil temperatures (gray line) closely tracked ambient.

did not differ in patterns of diffuse light interception and shade (diffuse: $F_{4,22}=2.06, P=0.12$; shade: $F_{4,22}=2.17, P=$ $0.106)$, nor did they differ in total daily proportions of diffuse light and shade (diffuse: $F_{1,3}=0.52, P=0.53$; shade: $F_{1,3}=$ $0.11, P=0.76$ ).

Most shade and diffuse light were created by self-shading within the leaf. Leaflets in P. triste projected upward, so with inclination of the rachis, leaflets became nearly perpendicular to a sun that is very low on the horizon in the morning during midwinter (fig. A5), thereby maximizing direct light interception early in the day $\left(F_{4,12}=6.21, P=0.006\right)$. In the early afternoon (1300 hours), vertically projecting leaflets resulted in minimal direct light exposure because, although the midribs of $P$. triste leaves were tracking the sun closely at this time, only the tips of the leaflets were exposed. Pelargonium lobatum leaves were flatter and more shallowly inclined throughout the day. In the early morning (0900 hours), less direct light fell on the leaves, and that intercepted was not perpendicular to the surface of the leaf.

Although average leaf temperatures of $P$. triste and P. lobatum were similar to each other and to ambient throughout most of the day, temperatures of localized regions subject to different light regimes differed between species (fig. 5; table A2). Point measures of temperatures in regions of the leaf experiencing direct light were similar in both species during hours of peak sun intensity, i.e., between 1100 and 1300 hours (fig. 5A). In $P$. triste, temperatures of sunlit regions closely matched those predicted by leaf energy budget equations while in P. lobatum these regions were significantly cooler than predicted. In the early morning (0900 hours), however, temperatures measured in direct light on $P$. triste were, on average, $2.8^{\circ} \mathrm{C}$ warmer than those for P. lobatum and they were warmer than ambient temperatures; shaded regions did not differ from ambient. In $P$. lobatum, on the other hand, early-morning sunlit temperatures 
Table 3

Results of ANOVAs for Each Time Period Comparing Average Leaf Temperatures of Pelargonium triste and Pelargonium lobatum to Each Other and to Ambient $(\Delta) T$

\begin{tabular}{lcrcccc}
\hline & & & & $P$. triste - & $\Delta T$ & $\Delta T$ \\
Time (hours) & df & \multicolumn{1}{c}{$F$} & $P$ & $P$. lobatum & P. triste & P. lobatum \\
\hline 0900 & 2,17 & 3.27 & .06 & .05 & .24 & .44 \\
1100 & 2,17 & 1.14 & .34 & .45 & .35 & 1.00 \\
1300 & 2,17 & .35 & .71 & .71 & .97 & .79 \\
1500 & 2,17 & .41 & .67 & .72 & .70 & 1.00 \\
1700 & 2,17 & 5.41 & .02 & .45 & .20 & .01 \\
\hline
\end{tabular}

Note. $\quad P$ values from Tukey HSD test indicate which effects were significant.

paralleled ambient temperatures (table A2), whereas shaded regions were nearly significantly colder than ambient $(P=0.07)$ and $P$. triste $(P=0.12)$. By 1500 hours, shaded regions of leaves in both species approached ambient temperatures, but later in the day, shade temperatures of P. lobatum leaves again were lower than those in P. triste, and both were lower than ambient.

\section{Shape, Movement, and Light Exposure Interact to Affect $\Delta \mathrm{T}$}

In order to determine whether shape and movement interact to affect the extent to which average leaf temperatures differed from ambient, we examined AICc comparisons of GAMMS (table 4). The best model (model 1) predicting $\Delta T$ included time of day, cosine $i$, LDI, the interaction between LDI and cosine $i$, and the proportion of direct light on the lamina. Including lamina area and SLA lowered support for the model. A simpler model without the interaction between cosine $i$ and shape, or without cosine $i$ (model 2), had somewhat less support, as did models that included other interactions (models 3 and 4). Diffuse light and shade were also included as variables throughout this analysis but had no effect.

\section{Discussion}

Here we show that in midwinter, two co-occurring, closely related geophytic Pelargonium species exhibit leaf movements consistent with solar tracking. Despite differences in blade shapes and leaf angles, leaf temperatures in both species closely track ambient throughout the day, except early in the morning. Three-dimensional aspects of shape and movement interact to result in differences in the relative amounts of direct light across the surface of the leaf throughout the day, but to our surprise, the proportion of direct light incident on the surface of the leaf alone poorly predicts how much average leaf temperatures deviate from ambient temperatures under winter growing conditions. The best predictive model also includes leaf shape and angle, as well as interaction of leaf shape and angle.

Energy budget theory predicts that leaves of smaller characteristic dimensions should track ambient temperatures closely, due to reduced insulation by boundary layers. Consistent with these predictions, $P$. triste did not warm much beyond ambient temperatures except in the cool, early morning, when the sun was low in the sky. At this time, the vertically oriented leaflets of $P$. triste increased the total surface area receiving direct sunlight. Consequently, at 0900 hours, temperatures of P. triste were warmer than ambient and $3.5^{\circ} \mathrm{C}$ warmer than the relatively flat leaves of $P$. lobatum. July is the coldest month at this site, with a mean temperature of $\sim 11^{\circ} \mathrm{C}$ (Schulze 2007), well below the $\sim 33^{\circ}-36^{\circ} \mathrm{C}$ range for optimum leaf temperatures for photosynthesis found in other species of Pelargonium (Nicotra et al. 2008). Therefore, we presume any leaf warming is favorable under winter growing conditions. In addition, the dissected lam-

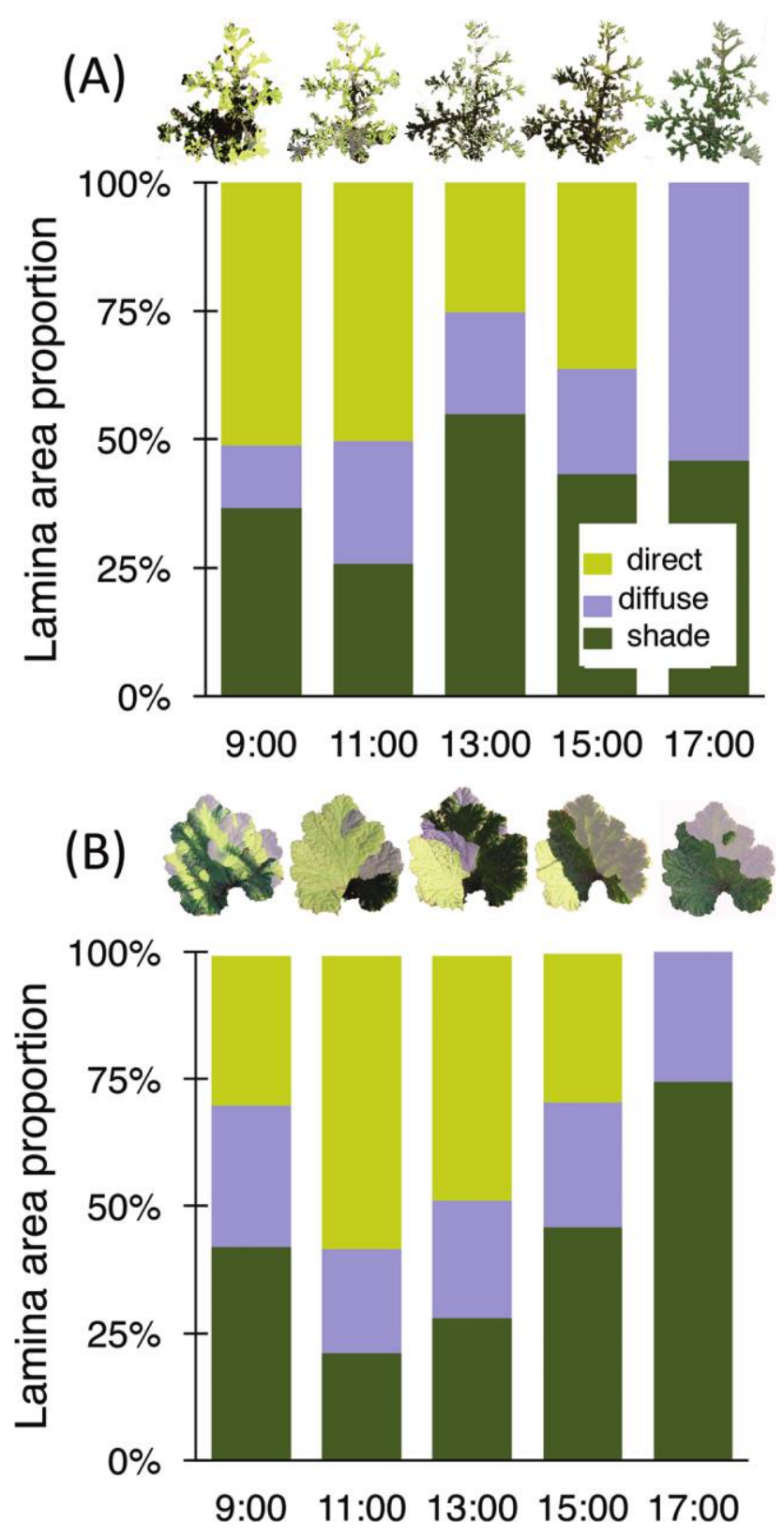

Fig. 4 Proportion of Pelargonium triste $(A)$ and Pelargonium lobatum $(B)$ lamina area exposed to direct light, diffuse light, and shade; bars represent mean of five leaves across the diurnal time course, and one representative leaf is shown above bars. Bar colors: light green = sun; gray $=$ diffuse light; dark green $=$ shade . 

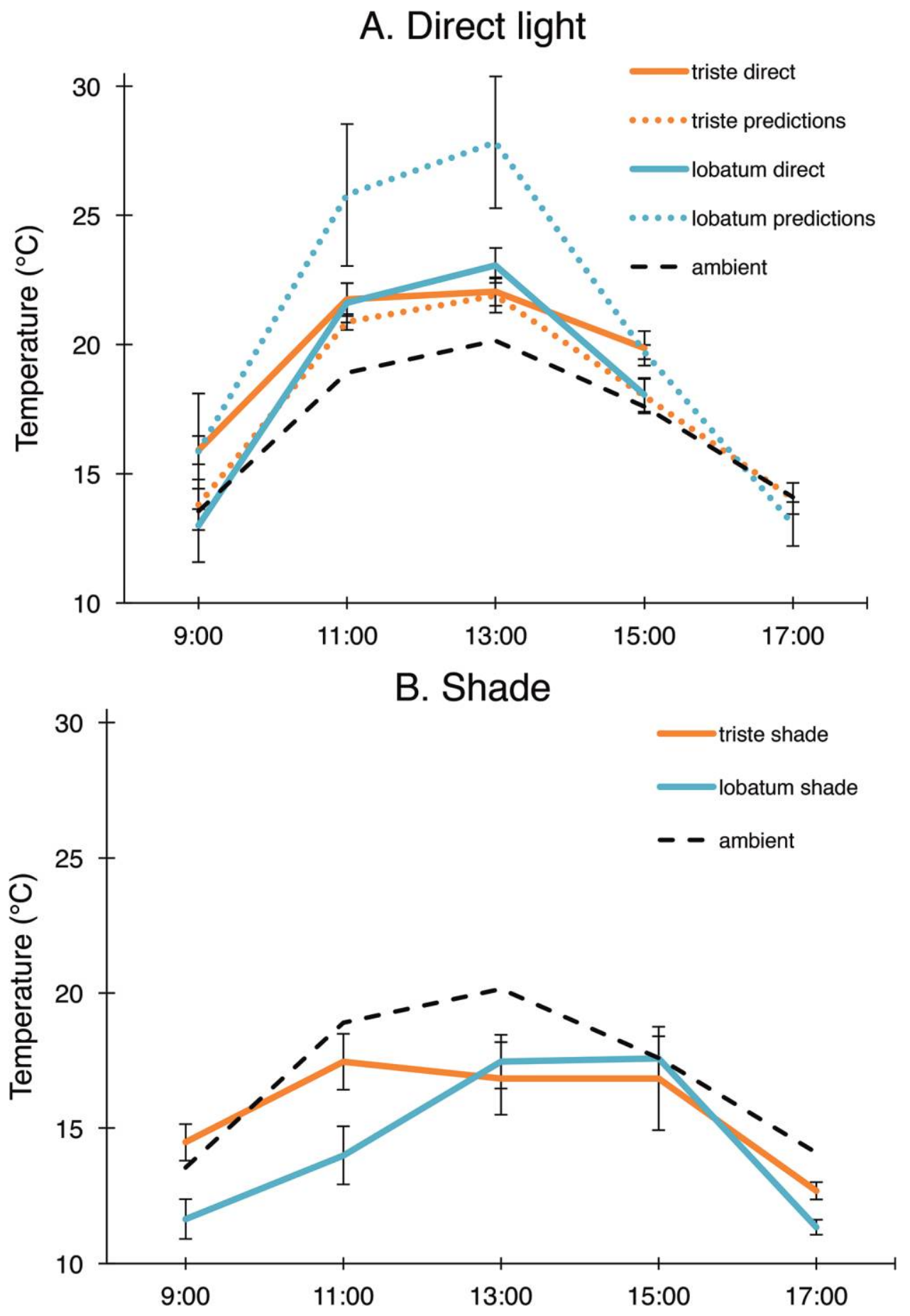

Fig. 5 Diurnal average temperatures of regions of the leaf with full sun exposure $(A)$ and in shade $(B)$. (Dotted lines are predicted temperatures from leaf energy budget calculations.) Bars represent the mean across all regions at that time period for each species \pm 1 SE. See table A2, available online, for $P$ values for comparisons. (Note that late in the day, none of our measures for Pelargonium triste were in fully exposed regions of the leaf surface.)

ina of $P$. triste may have been slightly warmer at sunrise than those of P. lobatum due to diminished radiational heat loss at night. Unfortunately, we don't have pre- and postsunrise temperatures for these species.
By early afternoon (1300 hours), when rachis orientation was perpendicular to the sun, only the outwardly projecting tips of $P$. triste leaflets were exposed to direct light. These leaflet tips were $3^{\circ} \mathrm{C}$ warmer than ambient. However, leaflet self-shading 


\section{Table 4}

Comparison of Generalized Additive Mixed Models for $\Delta T$ (Observed Leaf Temperature Minus Ambient Temperature)

\begin{tabular}{|c|c|c|c|c|}
\hline Model no. & Model variables for predicting $\Delta T$ & $\mathrm{AICc}$ & df & $\mathrm{dAICc}$ \\
\hline 1 & $\Delta T \sim$ hours $+\operatorname{cosI}+$ LDI + direct + LDI: $\cos I$ & 91.9 & 8 & .0 \\
\hline 2 & $\Delta T \sim$ hours + LDI + direct & 95.8 & 6 & 3.9 \\
\hline 3 & $\Delta T \sim$ hours + LDI + direct + LDI: direct & 96.1 & 7 & 4.2 \\
\hline 4 & $\Delta T \sim$ hours $+\operatorname{cosI}+$ LDI + direct & 96.4 & 7 & 4.4 \\
\hline 5 & $\Delta T \sim$ hours + cosI + LDI + SLA + lam_area & 104.1 & 8 & 12.2 \\
\hline 6 & $\Delta T \sim$ hours $+\operatorname{cosI}+$ LDI & 107.1 & 6 & 15.2 \\
\hline 7 & $\Delta T \sim$ hours + LDI & 108.3 & 5 & 16.4 \\
\hline 8 & $\Delta T \sim$ hours + direct & 183.9 & 5 & 92.0 \\
\hline
\end{tabular}

Note. The best models for $\Delta T$ include hours (time since 0900 hours), cosine $i$ (cosI), leaf dissection index (LDI), the proportion of lamina area intercepting direct light (direct), specific leaf area (SLA), and lamina area (lam_area). AICc is a parameter that describes model fit (smaller values indicate better models), and dAICc is the difference in AICc from the best model. When dAICc values are similar, as in the case for the top four models above, the preferred model is the one with the fewest variables.

at their base resulted in more than half of the leaf surface being shaded and $3^{\circ} \mathrm{C}$ cooler than ambient. Consequently, average leaf temperatures matched ambient. Presumably, dissection of the leaf blade into leaflets affects leaf temperature more than photosynthesis because leaflets scatter incident light (Rich et al. 1995) and while diffuse light is highly effective for photosynthesis (Alton et al. 2007), it has little effect on leaf temperature. That leaflets of $P$. triste are able to utilize scattered, diffuse light is further supported by the isolateral distribution of palisade mesophyll cells in this species (fig. A6). Palisade cell distribution has been associated with the direction and quality of light across a range of species (Vogelmann and Martin 1993) and has been shown to be correlated with three-dimensional leaf shape and leaf orientation (Smith et al. 1997, 1998; Ustin et al. 2001; Habermann et al. 2011; Joesting et al. 2012). It is likely that dissected leaves present an additional advantage in late spring, prior to leaf senescence, when rainfall declines and ambient temperatures increase. Under these conditions, when the sun is directly overhead in the middle of the day, the area of the leaf experiencing internal self-shading would increase, thereby lowering average leaf temperatures and potentially restricting photoinhibition.

Perhaps our more surprising result is that average leaf temperatures of $P$. lobatum also remain near ambient. Even if we restrict our focus to only point measures in sunlit regions of the leaf at midday, when the sun is highest in the sky, these regions of the leaf were warmer than ambient but still never reached temperatures $7^{\circ} \mathrm{C}$ above ambient that were predicted by energy budget calculations. We attribute the differences between observed and predicted leaf temperatures to several causes. One is that the energy budget calculator we used assumes uniform conditions of incident light across the entire surface of the leaf, which was not the case. While sunlit surfaces were $3^{\circ} \mathrm{C}$ warmer than ambient, even at 1100 hours, no more than $60 \%$ of the leaf surface received direct light, and this proportion diminished over the course of the day. At the same time, shaded regions of the leaf were $6^{\circ} \mathrm{C}$ cooler than ambient, a difference that would dramatically lower average leaf temperatures. Later in the day, at 1500 hours, both shaded and directly sunlit leaves paralleled ambient temperatures, and these were still less than predicted. Neither can the discrepancy between measured and modeled temperatures in P. lobatum be ex- plained by conductance, because even when the higher values of conductance measured with the Li-Cor in 2015 were substituted into the energy budget equation, the new predicted temperatures were close to those predicted based on the 2008 conductance measures. We attribute the higher conductance values measured by the Li-Cor to chamber parameters that maximized photosynthetic rates.

The discrepancy between predicted and measured temperatures in P. lobatum is easier to understand for temperatures measured in the early morning and late afternoon. At these times, temperatures of $P$. lobatum in direct light were indistinguishable from ambient (table A2). In shaded regions of $P$. lobatum, leaves were actually cooler than ambient by $2^{\circ}$ and $2.8^{\circ} \mathrm{C}$ early and late in the day, respectively. These lower shade temperatures likely resulted from thicker boundary layers that trapped cool air against the abaxial leaf surface in regions not subject to warming by direct light absorption (e.g., Bridge et al. 2013). Damp, sandy soils are likely to be cooler than ambient in the morning and close to ambient later in the day (Nobel and Geller 1987). Thus, a combination of decreased earlymorning direct light absorption and leaf and soil boundarylayer effects in the larger, less lobed leaves of $P$. lobatum likely combine to explain why its leaf temperatures were lower than ambient early in the morning and later in the day. We also cannot eliminate possible effects of increased radiational cooling at night, relative to $P$. triste.

Despite differences in angle and leaf shape, both species showed the same proportion of total daily direct light interception, a finding that has been previously observed in other geophytic rosette species (Geller and Smith 1982). Although incident light exposure clearly influences local temperatures within the leaf, the proportion of direct light exposure, in the absence of leaf morphology and angle, poorly explained average leaf temperatures at any given time. The added effects of leaf morphology and angle likely include localized boundary-layer effects, as well as increased photon flux density associated with the angles more perpendicular to the sun (Ehleringer and Werk 1986). In addition, other confounding factors influence leaf temperature, such as differences in SLA, leaf water content, and leaf thickness (Leigh et al. 2012, 2017), as well as ground surface roughness and its influence on wind speed and air turbulence. Presumably, we have controlled for some of these factors by choosing closely 
related species in the same habitat, but, even so, species differed in SLA and leaf water content.

Whether leaf shape and movement interact more generally across a broader array of species is unknown, as this is the first study we know of to have specifically compared movement in two species differing in leaf shape while controlling for phylogeny. Others have suggested a tendency for smaller leaves to be positioned at steeper angles (e.g., Smith et al. 1997), but whether this effect is driven by leaf size per se, by effective leaf width, or by fixed leaf angles versus diurnal movement is not clear. Among 14 species of Pelargonium that vary in growth form, cosine $i$ at midday was positively correlated with the extent of lamina dissection but not with total leaf area (fig. A7). These data suggest that at least in Pelargonium, both two- and three-dimensional leaf shapes interact with leaf angle, achieved via movement or fixed branching patterns. This interaction influences leaf thermal profiles by influencing boundary layers and the extent and amount of direct light absorption over the course of the day.

\section{Conclusions}

Two geophytic species growing next to each other with dramatically different leaf shapes maintain similar temperatures over the course of the day, except in the early morning, when highly dissected vertically oriented leaflets are warmer. During the winter growing season, average leaf temperatures of both species track ambient temperatures and remain cooler than would be predicted from leaf energy budget calculations that assume uniform illumination across the surface of the leaf. Leaf shape and movement interact to maintain the same total proportion of leaf surface exposed to direct sunlight throughout the day in both species, but shape and movement have additional effects on leaf temperature beyond controlling the proportion of direct incident light, which are likely mediated though their effect on boundary layers. Three-dimensional leaf shape is key to fully understanding leaf thermal profiles under field conditions.

\section{Acknowledgments}

We thank CapeNature for collection permits and De Hoop Nature Reserve for permission to collect. Thanks also to R. Chazdon, D. Ray, J. Silander, A. Singh, C. Schlichting, and anonymous reviewers for helpful comments on earlier drafts of the manuscript. Funding was provided to K. Mocko by NSF-IRE (OISE-0623341) and to K. Mocko and C. Jones by NSF-Dimensions of Biodiversity (1046328).

\section{Literature Cited}

Adobe Photoshop 2008 CS4 Extended. Adobe Systems, San Jose, CA. Alton PB, R Ellis, SO Los, PR North 2007 Improved global simulations of gross primary product based on a separate and explicit treatment of diffuse and direct sunlight. J Geophys Res Atmos 112:D07203.

Bakker FT, A Culham, P Hettiarachi, T Touloumenidou, M Gibby 2004 Phylogeny of Pelargonium (Geraniaceae) based on DNA sequences from three genomes. Taxon 53:17-28.

Balding FR, GL Cunningham 1976 A comparison of heat transfer characteristics of simple and pinnate leaf models. Bot Gaz 137:6574.

Bridge LJ, KA Franklin, ME Homer 2013 Impact of plant shoot architecture on leaf cooling: a coupled heat and mass transfer model. I R Soc Interface 10:20130326.

Chelle M 2005 Phylloclimate or the climate perceived by individual plant organs: what is it? How to model it? What for? New Phytol 166:781-790.

Cornwall C, A Horiuchi, C Lehman 2014 Solar position calculator. Vol. 2009. National Oceanic and Atmospheric Administration Surface Radiation Research Branch.http://www.srrb.noaa.gov/highlights /sunrise/azel.html. Accessed June 8, 2009.

Cowling R, D Richardson, S Pierce 1997 Vegetation of southern Africa. Cambridge University Press, New York.

Darwin C 1881 The power of movement in plants. Appleton, New York.

dos Santos A, L Rosa, L Franke, C Nabinger 2006 Heliotropism and water availability effects on flowering dynamics and seed production in Macroptilium lathyroides. Rev Bras Sementes 28:45-52.

Ehleringer JR, IN Forseth 1980 Solar tracking by plants. Science 210:1094-1098.

1989 Diurnal leaf movements and productivity in canopies. Pages 129-142 in G Russell, B Marshall, PG Jarvis, eds. Plant canopies: their growth, form and function. SEB SEminar SEries 31. Cambridge University Press, Cambridge.
Ehleringer JR, KS Werk 1986 Modifications of solar-radiation absorption patterns and implications for carbon gain at the leaf level. Pages 57-82 in TJ Givnish, ed. On the economy of plant form and function. Cambridge University Press, New York.

Fleck S, U Niinemets, A Cescatti, JD Tenhunen 2003 Three-dimensional lamina architecture alters light-harvesting efficiency in Fagus: a leafscale analysis. Tree Physiol 23:577-589.

Forseth IN, JR Ehleringer 1980 Solar tracking response to drought in a desert annual. Oecologia 44:159-163.

1982 Ecophysiology of two solar tracking desert winter annuals. II. Leaf movements, water relations and microclimate Oecologia 54:41-49.

1983 Ecophysiology of two solar tracking desert winter annuals. III. Gas exchange responses to light, $\mathrm{CO}_{2}$ and VPD in relation to long-term drought. Oecologia 57:344-351.

Forseth IN, AH Teramura 1986 Kudzu leaf energy budget and calculated transpiration: the influence of leaflet orientation. Ecology 67:564-571.

Foster K, MH Ryan, D Real, P Ramankutty, H Lambers 2013 Seasonal and diurnal variation in the stomatal conductance and paraheliotropism of tedera (Bituminaria bituminosa var. Albomarginata) in the field. Funct Plant Biol 40:719-729.

Galvez D, RW Pearcy 2003 Petiole twisting in the crowns of Psychotria limonensis: implications for light interception and daily carbon gain. Oecologia 135:22-29.

Gates DM 1980 Biophysical ecology. Springer, New York.

Gates DM, R Alderfer, SE Taylor 1968 Leaf temperature of desert plants. Science 159:994-995.

Geller G, W Smith 1982 Influence of leaf size, orientation, and arrangement on temperature and transpiration in three high-elevation, large-leafed herbs. Oecologia 53:227-234.

Goldblatt P, J Manning 2000 Cape plants: a conspectus of the cape flora of South Africa. National Botanical Institute of South Africa, Pretoria, and The Missouri Botanical Garden Press, St. Louis, MO. 
Gottschlich DE, AP Smith 1982 Convective heat transfer characteristics of toothed leaves. Oecologia 53:418-420.

Greer DH, MR Thorpe 2009 Leaf photosynthetic and solar-tracking responses of mallow, Malva parviflora, to photon flux density. Plant Physiol Biochem 47:946-953.

Habermann G, PFV Ellsworth, JL Cazoto, AM Feistler, L da Silva, DA Donatti, SR Machado 2011 Leaf paraheliotropism in Styrax camporum confers increased light use efficiency and advantageous photosynthetic responses rather than photoprotection. Environ Exp Bot 71:10-17.

Hegazy AK, MI El Amry 1998 Leaf temperature of desert sand dune plants: perspectives on the adaptability of leaf morphology. Afr Ecol 36:34-43.

Joesting HM, MO Sprague, WK Smith 2012 Seasonal and diurnal leaf orientation, bifacial sunlight incidence, and leaf structure in the sand dune herb Hydrocotyle bonariensis. Environ Exp Bot 75:195-203.

Kern SO, MJ Hovenden, GJ Jordan 2004 The impacts of leaf shape and arrangement on light interception and potential photosynthesis in southern beech (Nothofagus cunninghamii). Funct Plant Biol 31:471-480.

Leigh A, R Hill, MC Ball 2014 Leaf shape influences spatial variation in photosynthetic function in Lomatia tinctoria. Funct Plant Biol 41:833-842.

Leigh A, S Sevanto, MC Ball, JD Close, DS Ellsworth, CA Knight, AB Nicotra, S Vogel 2012 Do thick leaves avoid thermal damage in critically low wind speeds? New Phytol 194:477-487.

Leigh A, S Sevanto, JD Close, AB Nicotra 2017 The influence of leaf size and shape on leaf thermal dynamics: does theory hold up under natural conditions? Plant Cell Environ 40:237-248.

López A, FD Molina-Aiz, DL Valera, A Peña 2012 Determining the emissivity of the leaves of nine horticultural crops by means of infrared thermography. Sci Hortic 137:49-58.

McDonald PG, CR Fonseca, JM Overton, M Westoby 2003 Leafsize divergence along rainfall and soil-nutrient gradients: is the method of size reduction common among clades? Funct Ecol 17:5057.

Medina E, MA Sobrado, R Herrera 1978 Significance of leaf orientation for leaf temperature in an amazonian sclerophyll vegetation. Radiat Environ Biophvs 15:131-140.

Mooney HA, JR Ehleringer 1978 The carbon gain benefits of solar tracking in a desert annual. Plant Cell Environ 1:307-311.

Nicotra AB, MJ Cosgrove, A Cowling, CD Schlichting, CS Jones 2008 Leaf shape linked to photosynthetic rates and temperature optima in South African Pelargonium species. Oecologia 154:625635.

Nicotra AB, A Leigh, CK Boyce, CS Jones, KJ Niklas, DL Royer, H Tsukaya 2011 The evolution and functional significance of leaf shape in the angiosperms. Funct Plant Biol 38:535-552.

Nobel PS 1983 Biophysical plant physiology and ecology. WH Freeman, San Francisco.

Nobel PS, GN Geller 1987 Temperature modelling of wet and dry desert soils. IEcol 75:247-258.

Parkhurst D, O Loucks 1972 Optimal leaf size in relation to environment. Ecology 60:505-537.
Pincebourde S, HA Woods, C Fox 2012 Climate uncertainty on leaf surfaces: the biophysics of leaf microclimates and their consequences for leaf-dwelling organisms. Funct Ecol 26:844-853.

Pritchard JM, IN Forseth 1988 Rapid leaf movement, microclimate, and water relations of two temperate legumes in three contrasting habitats. Am I Bot 75:1201-1211.

R Development Core Team 2012 R: a language and environment for statistical computing, version 2.15.2. R Foundation for Statistical Computing, Vienna. http://www.R-project.org/.

Rich PM, NM Holbrook, N Luttinger 1995 Leaf development and crown geometry of two iriarteoid palms. Am I Bot 82:328-336.

Rosa LM, IN Forseth 1996 Diurnal patterns of soybean leaf inclination angles and azimuthal orientation under different levels of ultraviolet-b radiation. Agric For Meteorol 78:107-119.

Schuepp PH 1993 Leaf boundary layers. New Phytol 125:477-507.

Schulze RE 2007 The South African atlas of agrohydrology and climatology. WRC report 1489/1/06. Water Research Commission, Pretoria, South Africa.

Smith WK, DT Bell, KA Shepherd 1998 Associations between leaf structure, orientation, and sunlight exposure in five western Australian communities. Am I Bot 85:56-63.

Smith WK, PS Nobel 1978 Influence of irradiation, soil water potential, and leaf temperature on leaf morphology of a desert broadleaf, Encelia farinosa Gray (Compositae). Am I Bot 65:429-432.

Smith WK, TC Vogelmann, EH De Lucia, DT Bell, KA Shepherd 1997 Leaf form and photosynthesis. Bioscience 47:785-793.

Sousa W 2003 Tleaf2.Xls: leaf energy balance simulation program. In $\mathrm{T}$ Dawson, ed. Laboratory exercise for plant ecophysiology. University of California, Berkeley, CA. http://ib.berkeley.edu/courses /ib151/Tleaf2.xls. Accessed June 10, 2014.

Ustin SL, S Jacquemoud, Y Govaerts 2001 Simulation of photon transport in a three-dimensional leaf: implications for photosynthesis. Plant Cell Environ 24:1095-1103.

Valiente-Banuet A, M Verdu, F Valladares, P Garcia-Fayos 2010 Functional and evolutionary correlations of steep leaf angles in the mexical shrubland. Oecologia 163:25-33.

van Zanten M, TL Pons, JAM Janssen, L Voesenek, AJM Peeters 2010 On the relevance and control of leaf angle. Crit Rev Plant Sci 29:300-316.

Vogel S 1970 Convective cooling at low airspeed and the shapes of broad leaves. I Exp Bot 21:91-101.

2009 Leaves in the lowest and highest winds: temperature, force and shape. New Phytol 183:13-26.

Vogelmann T, G Martin 1993 The functional significance of palisade tissue: penetration of directional versus diffuse light. Plant Cell Environ 16:65-72.

Werk KS, JR Ehleringer 1984 Non-random leaf orientation in Lactuca serriola L. Plant Cell Environ 7:81-87.

Wood S 2017 Mixed GAM computation vehicle with automatic smoothness estimation. R package, version 1.8-22. https://cran.r-project.org /web/packages/mgcv/index.html.

Zhang YL, HZ Zhang, GY Feng, JS Tian, WF Zhang 2009 Leaf diaheliotropic movement can improve carbon gain and water use efficiency and not intensify photoinhibition in upland cotton (Gossypium hirsutum L.). Photosynthetica 47:609-615. 